\title{
DETERMINATION OF URANIUM AND THORIUM IN SEMICONDUCTOR MEMORY \\ MATERIALS BY HIGH FLUENCE NEUTRON ACTIVATION ANALYSIS
}

F. F. Dyer, J. F. Emery, and K, J. Northeutt

\section{MASTER} Analytical Chemistry Division Oak Ridge National Laboratory* Dak Ridge, Tennessee 37830 (USA)

$$
\text { and }
$$

R. M. Scott

International Business Machines - East Fishkill Facility Hopewel1 Junction, New York 12533 (USA)

Paper to be presented at the Sixth International Conference, "Modern Trends in Activation Analysis," June 15-19, 1981, University of Toronto, CA and to be published in the Journal of Radioanalytical Chemistry.

BY ACCEPTANCE OF THIS ARTICLE, THE PUBLISHER

OR RECIPIENT ACKNOWLEDGES THE U.S. GOVERNMENT'S

RIGHT TO RETAIN A NONEXCLUSIVE, ROYALTY-FREE LICENSE IN AND TO ANY COPYRIGHT COVERING THE ARTICLE.

\footnotetext{
*Operated by Union Carbide Corporation for the U.S. Department of Energy, under Contract No. W-7405-eng-26.
}

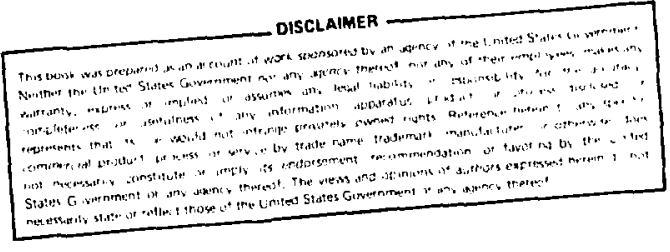




\title{
DETERMINATION OF URANIUM AND THORIUM IN SEMICONDUCTOR MEMORY
}

MATERIALS BY HIGH FLUENCE NEUTRON ACTIVATION ANALYSIS

\author{
F. F. Dyer, J. F. Emery, and K. J. Northcutt \\ Analytical Chemistry Division, Oak Ridge National Laboratory* \\ Oak Ridge, Tennessee 37830 (USA) \\ and
}

R. M. Scott.

International Business Machines - East Fishkill Facility

Hopewe11 Junction, New York, 12533 (USA)

\begin{abstract}
3.

Uranium and thorium were measured by absolute neutron activation analysis in high-pirity materials used to manufacture semiconductor memories. The main thrust of the study concerned aluminum and aluminum alloys used as sources for thin film preparation, evaported metal films, and samples from the Czochralski silicon crystal process. Average levels of $U$ and Th were found for the source alloys to be $\sim 65$ and $\sim 45 \mathrm{ppb}$, respectively. Levels of $U$ and Th in silicon samples fell in the range of a few parts per trillion. Evaporated metal films contained about $1 \mathrm{ppb} U$ and $T h$, but there is some question about these results due to the possibility of contamination.
\end{abstract}

*Operated by Union Carbide Corporation for the U.S. Department of Energy, under Contract No. W-7405-eng-26. 


\section{Introduction}

The determination of uranium and thorium in high-purity materials used to manufacture. semiconductor memories was investigated by high-fluence neutron activation analysis. The impetus for this study was the so-called "soft error" effect ${ }^{l}$ caused in computer memories by the ionizing alpha particles emitted by uranium and thorium and their daughters. Materials investigated included wafers from silicon crystals, crucibles, silicon melts remaining after crystal formation, aluminum and aluminum-copper alloy source materials zone refined to "five nines" purity, experimental aluminum metal specimen, and a few other special samples. Most of the experimental aluminum and many of the aluminum copper samples were alpha counted before they were analyzed for uranium and thorium and these data are reported.

\section{Experimental}

\section{Overview}

Uranium and thorium were determined in all samples by absolute (parametric) activation analysis. This approach to neutron activation analysis has been in use for many years at Oak Ridge National Laboratory, and although not applicable to all types of sample materials, has been applied successfully for a large number of analyses typified by references 2 and 3 . This method, which was used by Schmidt and Pearce 4 for a detailed study of transition group metal contamination in silicon device manufacturing, was acclaimed for its economy and accuracy and was recommended for the measurement of uranium in these materials. The method has been found to be eminently suitable for the 
determination of uranium and thorium in the materials studied in the present work in which over 170 samples have been analyzed.

Uranium in many of the aluminum-copper alloys containing the higher levels of uranium and thorium was determined by both delayed-neutron counting and by gamma spectroscopy measurements of the ${ }^{239} \mathrm{~Np}$ formed by the reactions : $238_{\mathrm{U}}(\mathrm{n}, \gamma){ }^{239} \mathrm{U} \stackrel{\beta}{\rightarrow} 239^{\mathrm{Np}}$. Delayed neutron counting of uranium is based on the fact that several of the fission products of $235_{\mathrm{U}}$ emit neutrons following beta decay of precursor fission products. The neutrons can be counted and related to the uranium content of a sample from neutron counts obtained from a standard sample containing a known amount of uranium of known isotopic abundance. Thorium was measured by counting the $233_{\mathrm{Pa}}$ formed by the reactions: $\quad 232 \mathrm{Th}(\mathrm{n}, \gamma)^{233} \mathrm{Th} \stackrel{\beta}{\rightarrow} 233 \mathrm{~Pa}$. Most analyses made by gamma spectroscopy were effected by nondestructive counting following suitable decay times after neutron irradiation. In a few of the experimental aluminum films, radionuclides were formed that prevented nondestructive counting, and it was necessary to chemically isolate the ${ }^{239} \mathrm{~Np}$ and ${ }^{233} \mathrm{~Pa}$ before they could be measured. In some instances it was possible to determine uranium by delayed neutron counting and then after higher fluence irradiations and longer decay times measure the thorium nondestructively thus circumventing some chemistry.

Delayed neutron counting

Delayed neutron counting was carried out by irradiation in the pneumatic tube of the Oak Ridge Research Reactor. This counting facility and the analysis prccedures were described by Dyer et al.5 Samples were packaged in high density polyethylene rabbits with threaded lids, irradiated $60 \mathrm{~s}$ in a neutron flux of $\sim 5 \times 10^{13} \mathrm{n} \cdot \mathrm{cm}^{-2} \mathrm{~s}^{-1}$, allowed to decay $12 \mathrm{~s}$, and counted $40 \mathrm{~s}$. The 
neutron detector-moderator assembly consists of a polyethylene block traversed through its center by the pneumatic flight tube. Three six-membered arrays of 5-cm diam $\mathrm{BF}_{3}$ neutron counting tubes are located axially in the moderator around the flight tube in a staggered pattern at 7,12 , and $14 \mathrm{~cm}$ radii. An annulv; of lead with a $2.5 \mathrm{~cm}$ wall surrounds the flight tube at the location where the rabbit is stopped for counting. The combination of lead shielding and high-speed electronic counters serve to discriminate against counting gamma pile-up events due to the high gamma fields of the larger aluminum samples. Without the lead, it was estimated that the dose rate at the inner row of tubes immediately after irradiation of a $3 \mathrm{~g} \mathrm{Al}$ sample is $\sim 500 \mathrm{rad}$. In spite of the lead and fast electronics, initial measurements were found to be biased by the gama rays. The bias, inferred from an observed correlation between sample weight and derived $U$ iconcentration, was eliminated by disconnecting the inner row of detectors. Although useful analyses can be made at uranium concentrations of about $25 \mathrm{ppb}$, the ultimate sensitivity is limited by a background count from an irradiated empty rabbit that is equivalent to about 200 nanograms of natural uranium. No other interferences were present in the samples analyzed.

\section{High fluence analyses}

Irradiations for gamma spectroscopy measurements of ${ }^{239} \mathrm{~Np}$ and ${ }^{233} \mathrm{~Pa}$ were made in the pneumatic tube system of the High Flux Isotope Reactor (HFIR). This facility, which was previously described, 3 has a thermal neutron flux of $\sim 5 \times 10^{14} \mathrm{n} \cdot \mathrm{cm}^{-2} \mathrm{~s}^{-1}$ and a thermal-to-resonance flux ratio of 38. Irradiations were made in rabbits fabricated from reactor-grade graphite for periods of time of $10 \mathrm{~m}$ to $4 \mathrm{hr}$ corresponding to neutron fluences of $3 \times 10^{17}$ to $7 \times 10^{18} \mathrm{n} \cdot \mathrm{cm}^{-2}$. The rabbits are stopped on air columns at 
both ends of the flight tube and thus do not break. Irradiation of the aluminum samples, which become highly radioactive ( $100 \mathrm{Ci}$ per gram), are facilitated in the HFIR by virtue of the following features. The rabbit loading station, housed in a hot cell with remote manipulators, permits remote irradiation and handling of a series of samples without radiation exposure to personnel. The hot cell has $12.7 \mathrm{~cm}$ steel walls but does not provide complete protection from the intense penetrating radiation of the larger aluminum samples. For these samples, use is made of an in-pool rabbit holding station in the flight tube. These samples were brought to the holding station and allowed to decay for several minutes before they were returned to the hot cell.

Gamma spectra were acquired on a Nuclear Data 6620 computer-based MCA with three $\mathrm{Ge}(\mathrm{Li})$ detectors each of which had relative counting efficiencies of $\sim 20$ percent for ${ }^{60} \mathrm{Co}$.

A11 of the aluminum-copper, aluminum (except films), and other solids that contained relatively large $U$ and $T h$ levels were loaded directly in the graphite rabbits and washed in dilute hydrochloric acid to remove contaminants before they were counted. The aluminum and aluminum-copper samples were etched vigorously by the acid. Etching tests, made with unirradiated samples in solutions containing added amounts of ${ }^{239} \mathrm{~Np}$ and ${ }^{233} \mathrm{~Pa}$, showed that these nuclides did not electrochemically deposit on the samples. After they were etched, the surfaces of several irradiated samples were abraded with files and emery paper to determine if the surfaces were contaminated with ${ }^{239} \mathrm{~Np}$ and ${ }^{233} \mathrm{~Pa}$. These tests were negative. The copper content of the $\mathrm{Al}-\mathrm{Cu}$ materiais ranged from 5 to 18 percent and it was necessary to allow the induced ${ }^{64} \mathrm{Cu}$ (halflife $12.7 \mathrm{hr}$ ) to decay extensively before ${ }^{239} \mathrm{~Np}$ (half-1ife $56.4 \mathrm{hr}$ ) could be measured. Decay periods of 8-12 days were found to be about optimum for measuring ${ }^{239} \mathrm{~Np}$, which was determined from photopeak count-rates of the 106 
and $278 \mathrm{keV}$ gamma rays: Except for the Compton distribution of higher-energy gamma rays, the only interference to the measurement of the $278 \mathrm{keV} 1$ ine appeared to be the 279 line of ${ }^{75}$ Se formed from traces of Se. Corrections for this interference were necessary in samples whose uranium concentration was about $20 \mathrm{ppb}$ or less. No significant interference to measuring ${ }^{233} \mathrm{~Pa}$ via the $312 \mathrm{keV}$ line after these decay times was found.

All samples low in $U$ and $T h$ were handled with chrome-plated forceps inside plastic bags to lessen contamination from ambient dust. Silicon wafers were marked with a diamond scribe and broken. Aluminum films and silicon samples cut from wafers and taken from silicon crystals were encapsulated in aluminum foil (grocery store Reynolds Wrap) and irradiated usually for $1 \mathrm{hr}$ in graphite rabbits. The aluminum foil was found to contain $\sim 300 \mathrm{ppb}$ of uranium, and several fission products were observed in the silicon due presumably to recoil from the aluminum. Ali silicon samples were cleaned following irradiation by washing in the following liquids prior to counting: acetone, $\mathrm{H}_{2} \mathrm{O}, 6 \mathrm{~N} \mathrm{HCl}, \mathrm{H}_{2} \mathrm{O}$, $6 \mathrm{~N} \mathrm{NH} 4 \mathrm{OH}, \mathrm{H}_{2} \mathrm{O}$, acetone. The samples were then counted for periods of 16-27 hours after the ${ }^{31} \mathrm{Si}$ had decayed. Tungsten-187, due to $\sim 10 \mathrm{ppb}$ of tungsten in the silicon, was the major activity that somewhat limited the measurement sensitivity of ${ }^{239} \mathrm{~Np}$. Some samples were allowed to decay until the $187_{\mathrm{W}}$ was gone and recounted for ${ }^{233} \mathrm{~Pa}$. The possibility of contamination by uranium from the aluminum foil is discussed in the Results and Discussion section.

\section{Radiochemical separations}

Experimental aluminum that could not be measured nondestructively because of low $U$ and $T h$ and relatively high levels of ${ }^{64} \mathrm{Cu},{ }^{51} \mathrm{Cr}$, $198 \mathrm{Au}$, etc. were radiochemically processed to isolate the ${ }^{239} \mathrm{~Np}$ and 
${ }^{233} \mathrm{~Pa}$. A few Al-Cu samples were similarly processed. A separation procedure based on anion exchange with Dowex-1 in a nitric acid medium was adapted for use from information given by Burney and Harbour. 6 The method is simple to use and allows both ${ }^{239} \mathrm{~Np}$ and $233 \mathrm{Fa}$ to be isolated and counted together. Samples of aluminum were dissolved in 3-6 N HCl. Addition of $\mathrm{HNO}_{3}$ was necessary to dissolve the Al-Cu material. Solutions were evaporated to near dryness and finally adjusted to $8 \mathrm{~N}$ in $\mathrm{HNO}_{3}$. A few $\mathrm{ml}$ of $9.5 \mathrm{M}$ hydroxylamine hydrochloride was added to form $\mathrm{Np}(I V)$, and the solution was allowed to stand $\sim_{1} \mathrm{hr}$ and then passed through a Dowex-1 column pretreated with $8 \mathrm{~N} \mathrm{HNO}_{3}$. After ${ }^{64} \mathrm{Cu}$ and ${ }^{51} \mathrm{Cr}$ were eluted with $8 \mathrm{~N} \quad \mathrm{HNO}_{3},{ }^{239} \mathrm{~Np}$ and $233 \mathrm{~Pa}$ were eluted with $0.2 \mathrm{~N} \quad \mathrm{HNO}_{3}$, precipitated on $\mathrm{La}(\mathrm{OH})_{3}$ with $\mathrm{NH}_{4} \mathrm{OH}$, and counted. Gold-198 remains on the column. No significant interference in the Np-Pa fraction were found. Because the $U$ and Th levels were very low ( $1 \mathrm{ppb}$ ) in several of these samples, it was necessary to carry out the separation soon after irradiation ( $\sim 2$ days) when high levels of ${ }^{64} \mathrm{Cu}(\sim 1 \mathrm{mCi})$ were sometimes present. Other radiochemical procedures including extractions into TTA solutions and precipitations of various types were attempted before the one described was adopted. None provided sufficient decontamination from the massive amounts of ${ }^{64} \mathrm{Cu}$.

\section{Alpha counting}

Aluminum samples were alpha counted in IBM laboratories, using a scintillation method first described by Hallden and Harley in which a zinc sulfide phosphor is mounted on Mylar. The equipment was identical to that described by Bouldin. 8 The samples, which varied in size from 10 to $80 \mathrm{~cm}^{2}$, were placed on a layer of phosphor of identical size and counted on a 5-inch multiplier phototube for periods of time ranging from one week to one 
month. A background correction, obtained by counting a single-crystal silicon wafer, was applied to the measured count rates.

\section{Results and discussion}

The distributions of uranium and thorium in aluminum-copper alloys are shown in Figure 1 as bar graphs which give the concentrations of $U$ and $T h$ as parts per billion $\left(10^{9}\right)$ versus the number of samples which had approximately the same concentrations. Over 80 samples of the 99.999 percent pure alloys are represented by these data which serve to establish a data base for IBM aluminum-copper materials. These materials are used as sources in vacuum evaporators to lay down thin metal films. As can be seen, the concentrations vary widely ranglng in the case of uranium from $v 20$ to $\sim 140 \mathrm{ppb}$ and for thorium from $\sim_{3}$ to $\sim_{120}$ ppb.: The uranium data of Figure 1 are those that were derived from Instrumental gamma spectroscopy and do not include results of delayedneutron counting. Of the samples ( 230 ) that contained sufficient $U$ to be measured by delayed-neutron counting, agreement with instrumental gama spectroscopy results within uncertainties of the two methods was generally found. However, the $U$ in about 10 of the samples containing the highest $U$ levels was observed by gama spectroscopy to be about twice that measured by delayed neutron count1ng. Interferences in the gamma spectroscopy method (from both fission and capture products) were suspected but none could be found beyond that from ${ }^{75} \mathrm{Se}$ mentioned earlier. Good agreement $(\sim 10 \%)$ was obtained between measurements of the 106 and $278 \mathrm{keV} 11$ nes of ${ }^{239} \mathrm{~Np}$. Radiochemical measurements that would serve as a referee were not nade. The possibility of depletion of the $235_{U}$ isotope in the uranium which would yleld low concentrations by 
delayed neutron counting was considered but was not tested and is doubted. It seems unlikely that surface contamination remained after the acid etching treatment discussed earlier.

Average concentrations of $U$ and $T$ h data shown in Figure 1 are listed in Table 1 as 65 and $45 \mathrm{ppb}$, respectively. Results found by delayed neutron counting would cause the average uranium concentration to be slightly lower. Alpha particle count rates which were found for the Al-Cu materials to lie between 0.02 to $0.03 \alpha^{\cdot} \mathrm{cm}^{-2}-\mathrm{h}^{-1}$ are also listed in Table 1 .

Also presented in Table $\mathrm{I}$ are the $\mathrm{U}$ and $\mathrm{Th}$ concentrations and alpha activities observed in low-alpha aluminum. Included are data for a sample of aluminum (first entry) obtained from Alcoa which had bêen zone refined by 75 passes some 17 years ago to a purity of 99.9999 percent. This sample, which had an alpha activity of $0.005 \pm 0.005 \alpha \cdot \mathrm{cm}^{-2}-\mathrm{h}^{-1}$, was observed to have a level of $U$ of $\sim 1.0 \mathrm{ppb}$ and a thorium concentration $\sim 0.3 \mathrm{ppb}$. These results, which were very encouraging, especially with regard to the age of the sample and its alpha activity, initiated an interest in low alpha aluminum.

Several experimental aluminum samples of purity greater than 99.999 percent were obtained from various aluminum refiners. Results for these materials, listed in Table 1 as L9-L12 and 01 and 02, indicate an improvement over those materials represented in Figure 1 of about a factor of 10 in the alpha activity and a factor of about 100 in the levels of uranium and thorium. It should be noted that none of these samples were cast into ingots before analysis because of the possibility of surface contamination that would influence the alpha activity measurement. All of the determinations of $U$ and Th were made by instrumental gamma spectroscopy after the samples were irradiated $1 \mathrm{hr}$ in the HFIR and etched in dilute HCl. 
Also included in Table 1 are results obtained from two experimental aluminum films, samples $J 3$ and F7, prepared by multiple evaporations on modified silicon wafers from which they were later removed. These films were produced from sources which were typical of the existing aluminum-copper alloys represented in Fig. 1.

Alpha count rates for two $\mathrm{J} 3$ specimen ranged from 0.000 to 0.006 as given; sample F7 was not counted. Thorium concentrations determined instrumentally in $\mathrm{J} 3$ and $\mathrm{F} 7$ were found to be 1.3 and $0.3 \mathrm{pPb}$, respectively. Uranium could not be measured instrumentally but was determined radiochemically to be $0.6 \mathrm{ppb}$ in $\mathrm{J} 3$ and $0.2 \mathrm{ppb}$ in $\mathrm{F7}$. Thorium values determined radiochemically were observed to be $4.7 \mathrm{ppb}$ in $\mathrm{J} 3$ and $0.4 \mathrm{ppb}$ in $\mathrm{F} 7$. Although these samples were handled with considerable care, they were prepared and irradiated three times and wrapped twice in the aluminum foil that contained $300 \mathrm{ppb} U$. It was not possible to acid etch these samples following irradiation, and it now seems likely that some unknown amount of contamination was introduced onto these samples especially before the radiochemical measurement.

The standard Czochralski process for producing single crystal silicon uses a quartz crucible with contributes low-level impurities to the silicon melt, silicon crystal, and thus to the wafers formed from the crystal. Uranium and thorium (and their daughters) are leached from the quartz and may contribute a very low alpha activity to the wafers. Given in Table 2 are uranium and thorium concentrations that were observed in a crucible, the silicon melt remaining after crystal formation, and a slice taken from the silicon crystal. The uranium in the quartz crucible, $300 \mathrm{ppb}$, was comparable to that reported by Schmidt and Pearce for a quartz furnace tube.4 The thorium level was observed to be $130 \mathrm{ppb}$. The levels of both $\mathrm{U}$ and $\mathrm{Th}$ found in the melt were about 100 times less than that observed in the quartz and likewise the $U$ and Th 
were reduced another factor of 100 in the unpolished slize of silicon. Concen-* trations of $U$ and $T h$ in six polished silicon wafers that were prepared from other crystals were found to be stillar to these observed in the unpolished slice. These data are given in Table 2 as samples L2 - L7. As indicated earlier, these analyses were made by wrapping the samples in aluminum foil, irradiating $1 \mathrm{hr}$ in the HFIR and then counting after decay of the ${ }^{31} \mathrm{Si}$. It was expectid that some amount of pre-irradiation contamination would occur, and the samples were washed in a series of solvents (see Experimental section) after irradiation. Two of the samples, $L 6$ and $\mathrm{L} 7$, were measured before and after they were cleaned and these results are presented in Table 2. Soon after these irradiations, the aluminum foil was found to contain $\sim 300 \mathrm{ppb}$ U. Gamma lines of fission products, including $131_{\mathrm{I}}$ and $140_{\mathrm{Ba}}$, were found in spectra of both the washed and untreated samples although the washing removed about half of these nuclides. The quantities of uranium that would produce the observed levels of fission products were calculated and found to be $\sim 2$ ng for the untreated and $\sim 1 \mathrm{ng}$ for the treated. These levels were $\sim 100$ times that derived from the ${ }^{239} \mathrm{~Np}$ measurements. Recoil of fission products from the aluminum foil was suspected, and calculations reveaied that for the estimated $5 \mathrm{~cm}^{2}$ area of foil that contacted the samples, about 4 ng of uranium was within recoll range $(\sim 10 \mu \mathrm{m}) .9$ These results are thus consistent. Although the fission products did not significantly interfere with the ${ }^{239^{N p}}$ measurement, it was decided to try to prevent the contamination. Attempts to make long irradiations in the HFIR with graphite rabbits lined with high-purity polyethylene (inserts) proved feasible, and a sample of L3 was thus prepared and irradiated $4 \mathrm{hrs}$. The sample was cleaned only in an air jet before counting. No fission products were observed in this sample. Levels of $U$ and Th are listed in Table 2. As can be seen, the $U$ found in this manner appears to be slightly lower than the levels observed in the other samples. It is clear from data for sample L6 that surface uranium was present that was removed by the 
cleaning. It is not completely evident, however, if surface contamination was present in the samples that were cleaned. The experience with sample L3 clearly indicated that levels of $U$ and $T h$ of $a$ few parts per trillion can be easily measured when enough neutron fluence is applied. To explore questions of low level surface contamination on silicon wafers will require sample preparation in cleaner environments than was practiced in this study.

Because this investigation was prompted by a desire to correlate softerror cates with alpha emitter concentrations, it seems pertinent to briefly discuss this topic in light of findings of this study. The semiconductor manufacturers have been using a barrier layer to isolate their memory devices from the remainder of the electronic package. 10 This technique has reduced the potential soit-error rate to a low value which is referred to as the residual soft-error rate. The residual soft-error rate can be influenced by alpha radiation originating in the barrier itself, the efficiency of the barrier to stop alpha particles that originate external to the memory device, alpha particles that arise internally, and cosmic radiation. Based on computed alpha activities of $U$ and $T h$ that were observed in silicon and estimates of alpha activities of the daughters of these nuclides, we have concluded that the internal contribution of alpha radiation very likely has a minor effect on the observed residual soft-error rate in current memory products. Although we have not unequivocally established baseline levels of $U$ and $T h$ in evaporated metal films, we believe that the effects of internal alpha emitters in device metallurgy (in this case aluminum) will be greater than that in silicon. The use of aluminum sources that are low in uranium and thorium and alpha particle activity, coupled with advances in evaporation process engineering of fer the possibility of further reduction of the residual soft-error rate for future memory devices. 


\section{Acknowledgments}

We wish to thank L. C. Bate for irradiating and J. W. Wade for counting many of the samples that were analyzed. 


\section{References}

1. T. C. MAY and M. H. WOODS, IEEE Transactions on Electron Devices, Vol. ED-26, No.. 1 (1979) 2.

2. E. RICCI, T. H. HANDLEY, and F. F. DYER, J. Radioanal. Chem., 19 (1974) 141.

3. W. S. LYON and J. F. EMERY, Int. J. Environ. and Chem. 4 (1975) 125.

4. P. F. SCHMIDT and C. W. PEARCE, J. Electrochem. Soc. 128 (1981) 630 .

5. F. F. DYER, J. F. EMERY, and G. W. LEDDICOTTE, A Comprehensive Study of the Neutron Activation Analysis of Uranium by Delayed Neutron Counting, ORNL-3342 Art. (1962).

6. G. A. BURNEY and R. M. HARBOUR, Radiochemistry of Neptunium, DOE Technical Information Center, Rept. No. TIC-NAS-NS-3060 (Dece-ber 1974) 90.

7. N. A. HALLDEN and J. H. HARLEY, Anal. Chem. 32 (1960) 1961.

8. D. BOULDIN, in Radioelement Analysis Progress and Problems, edited by Lyon, Ann Arbor Science (1980) 31 .

9. J. ALEXANDER and M. F. GAZDIK, Phys. Rev. 120 (1960) 874.

10. J. McLEOD, Electronic Design 28 (1980) 36. 
FIGURE

Fig. 1. Thorium and uranium distribution in aluminum-copper alloys. 
ORNL-DWG 81-10151

Th-U DISTRIBUTION IN AI-CU SCURCE MATERIALS

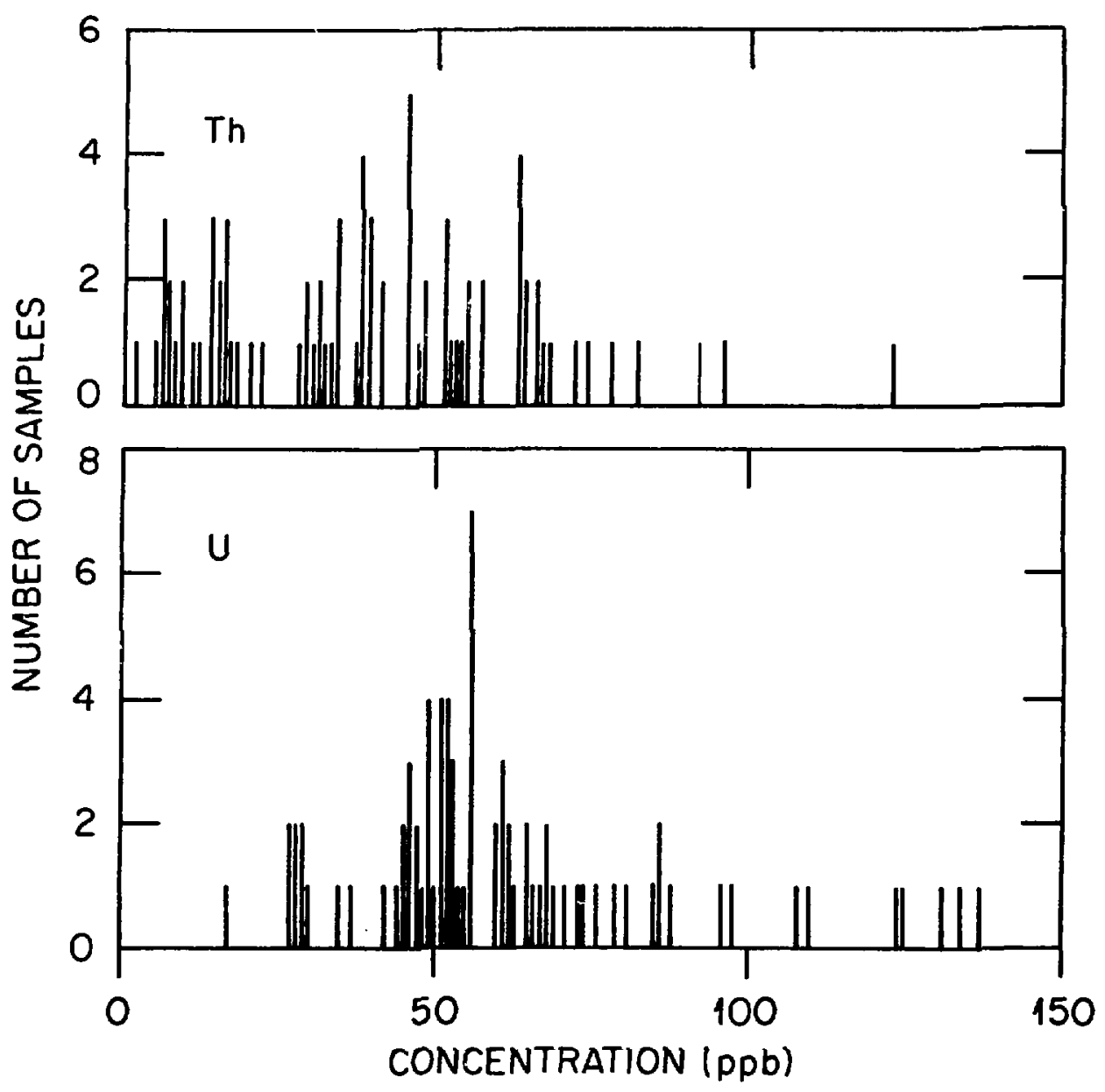


Table 1. Levels of uranium, thorium, and alpha activity observed in low alpha activity aluminum ${ }^{a}$

\begin{tabular}{|c|c|c|c|c|}
\hline Sample & Type & $U(p p b)$ & Th (ppb) & $\alpha / \mathrm{cm}^{2}-h$ \\
\hline $\begin{array}{l}16 \text { year old } \\
\text { Alcoa }\end{array}$ & Z.R. $75 x$ & $\leq 1.0$ & $\leq 0.3$ & $0.005 \pm 0.005$ \\
\hline Exp. \# L9 & Refined & $0.3+0.17$ & $\leq 0.2$ & $0.002 \pm 0.001$ \\
\hline \#L10 & Refined & $0.7 \pm 0.07$ & $\leq 0.06$ & $0.003 \pm 0.001$ \\
\hline \#L11 & Refined & $0.4 \pm 0.2$ & $<0.01$ & $0.003 \pm 0.001$ \\
\hline \#L12 & Refined & $6.4 \pm 0.6$ & $3.2 \pm 0.3$ & $\leq 0.03$ \\
\hline \#01 & Refined & $0.2 \pm 0.1$ & $\leq 0.1$ & $0.002 \pm 0.004$ \\
\hline \#02 & Refined & $10 . \pm 1$ & $3.3+0.3$ & $0.008 \pm 0.004$ \\
\hline $\begin{array}{l}\text { Typical IBM } \\
\text { Aluminum }\end{array}$ & Source material & $\sim 65$ & 245 & $0.02-0.03$ \\
\hline 非 3 & Evap. film & $0.6 \pm 0.06^{b}$ & $\begin{array}{l}1.3 \pm 0.7 \\
4.7 \pm 0.4^{b}\end{array}$ & $\begin{array}{l}0.000+0.001 \\
0.006 \pm 0.001 c\end{array}$ \\
\hline$\#$ F7 & Evap. film & $0.2 \pm 0.02^{b}$ & $\begin{array}{l}0.2+0.02 \\
0.4 \pm 0.04^{b}\end{array}$ & Not measured \\
\hline
\end{tabular}

Measured instrumentally except where noted.

${ }^{b}$ Measured radiochemically.

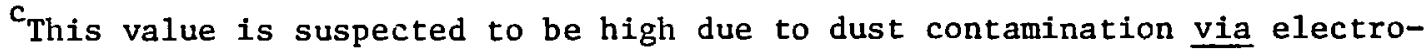
static charging of the thin film. 
Table 2. Uranium and thorium concentrations

in Czochralski Silicon Process ${ }^{a}$

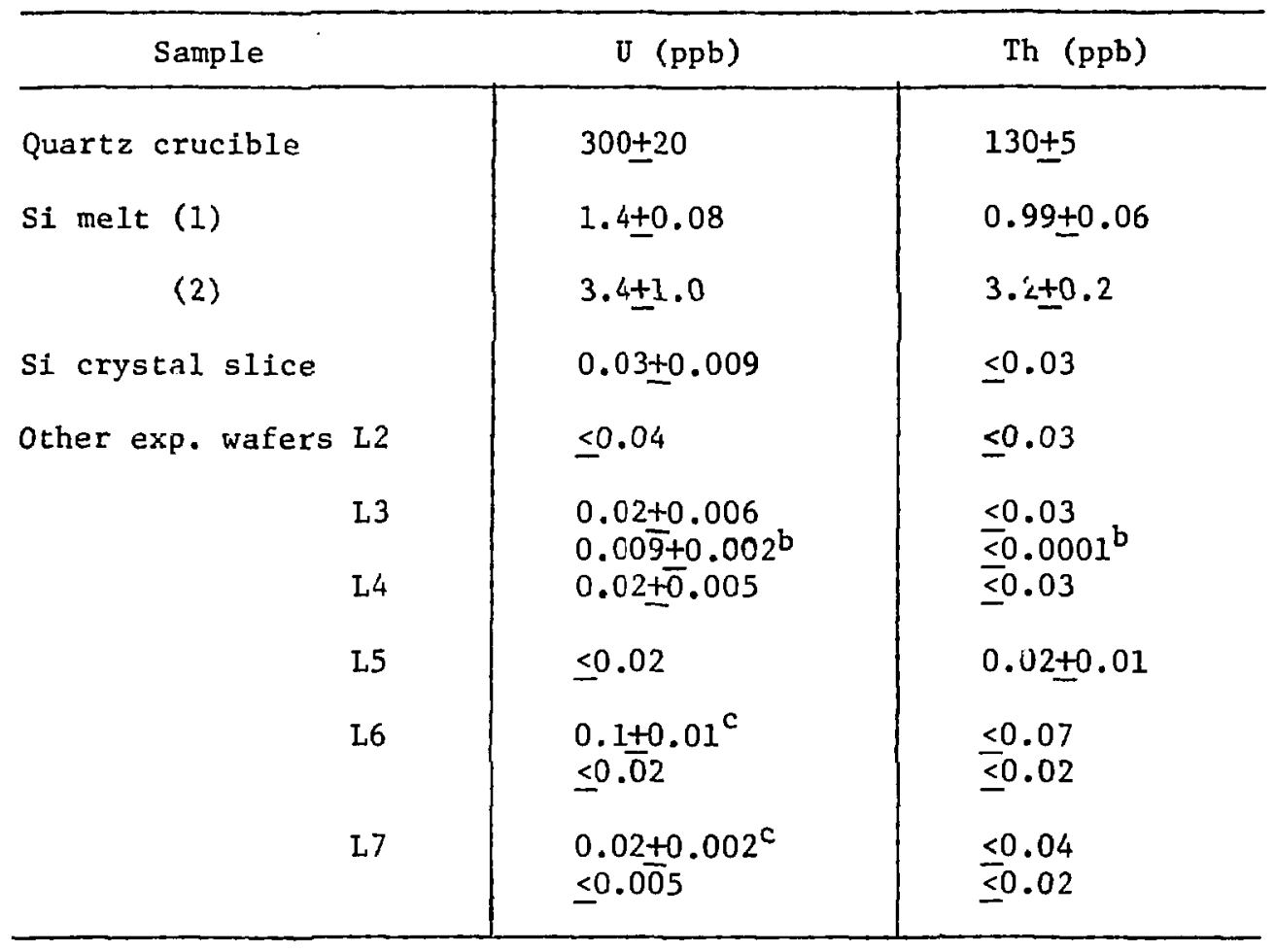

${ }^{a}$ Except where noted otherwise, samples were wrapped in aluminum foil irradiated to a fluence of $1.8 \mathrm{E} 18 \mathrm{n} \cdot \mathrm{cm}^{-2}$ cleaned in air jet, solvents (see text) and gamma counted.

${ }^{b}$ Sample was irradiated to fluence of $7 \mathrm{E} 18 \mathrm{n} \cdot \mathrm{cm}^{-2}$ in plastic container, cleaned in jet of air and counted.

${ }^{c}$ Samples were irradiated in aluminum foil and cleaned in air jet before counting. 